\title{
Adrenomedullin modulates the neurohumoral response to acute volume loading in normal conscious sheep
}

\author{
C J Charles, M G Nicholls, M T Rademaker and A M Richards \\ Christchurch Cardioendocrine Research Group, Christchurch School of Medicine, PO Box 4345, Christchurch, New Zealand \\ (Requests for offprints should be addressed to C J Charles; Email: chris.charles@chmeds.ac.nz)
}

\begin{abstract}
The physiological role of adrenomedullin (ADM) in volume and pressure homeostasis remains unclear. Accordingly, we assessed possible modulatory actions of ADM infusions on the neurohumoral response to acute volume loading with dextran in normal conscious sheep. Dextran $(15 \mathrm{ml} / \mathrm{kg})$, given with concurrent ADM $(5.5 \mathrm{pmol} / \mathrm{kg}$ per min - raising plasma ADM from below detection to approximately $10 \mathrm{pmol} / \mathrm{l})$ or vehicle control infusions, induced matched significant $(P<0 \cdot 001$ by ANOVA) falls in hematocrit $(27-30 \%)$ during both ADM and control and similar increases in right atrial pressure (approximately $10 \mathrm{mmHg}$ ). Compared with control, both systemic $(P=0.033)$ and pulmonary $(P=0.005)$ arterial pressure and peripheral resistance $(P=0 \cdot 004)$ were reduced during ADM but were raised post-infusion. The dextran-induced increase in cardiac output was augmented by ADM
\end{abstract}

$(P=0 \cdot 048)$. Dextran-induced increases in plasma atrial natriuretic peptide (ANP; $P=0 \cdot 008$ ), brain natriuretic peptide (BNP; $P=\mathrm{NS}$ ) and cyclic guanosine monophosphate (cGMP; $P=0.003$ ) were augmented post-ADM infusions. The dextran-induced fall in plasma renin activity (PRA) was attenuated by ADM $(P=0.039)$ whereas plasma aldosterone levels were unaltered. ADM augmented the increase in urinary volume during the second 2-h clearance period post-dextran.

Our data indicate that ADM modifies the hemodynamic and hormonal response to an acute volume challenge, enhances natriuretic peptide secretion and reduces systemic vascular resistance. These results provide further evidence that ADM plays a physiological role in volume and pressure homeostasis.

Journal of Endocrinology (2002) 173, 123-129

\section{Introduction}

Adrenomedullin (ADM) is a recently discovered 52 amino acid hormone. Although generally considered a paracrine agent, plasma concentrations of ADM in some conditions (including heart failure) are sufficient to suggest it may play a role in circulatory homeostasis (Richards et al. 1996). The ability of ADM to induce a potent and sustained reduction of arterial pressure has been demonstrated in a number of species including sheep (Parkes \& May 1995, Charles et al. 1997) and humans (Lainchbury et al. 1997). This is associated with clear-cut rises in cardiac output and dramatic falls in peripheral resistance (Parkes \& May 1995, Charles et al. 1997). ADM is natriuretic and diuretic in a number of animal models (Ebara et al. 1994, Hirata et al. 1995). Hormonal actions attributed to ADM include stimulation of renin-angiotensin system (Parkes \& May 1995, Charles et al. 1997, Rademaker et al. 1997) and suppression of aldosterone secretion (Nussdorfer et al. 1997, Petrie et al. 2000, Salemi et al. 2000). ADM may also modulate atrial natriuretic peptide (ANP) levels although conflicting publications report both inhibition (Sato et al. 1997) and stimulation (Rademaker et al. 1997).
Taken together, it appears that ADM may play a physiological role in volume and pressure homeostasis. However, the possible effects of ADM in the setting of acute volume loading are unknown. Acute volume loading can be reproducibly modeled in sheep by intravenous administration of dextran which induces marked falls in hematocrit, and rises in arterial and filling pressures and plasma levels of the natriuretic peptides in association with diuresis and natriuresis (Charles et al. 1991). We postulated that ADM would modulate these well-documented effects of acute volume loading. Accordingly, we assessed the effects of a low-dose infusion of ADM on the hemodynamic, hormonal and renal response to an acute volume (dextran) load in normal conscious sheep.

\section{Materials and Methods}

The study protocol was approved by the Animal Ethics Committee of the Christchurch School of Medicine. Eight Coopworth ewes (Lincoln University Farm, Christchurch, New Zealand) were housed in an air-conditioned lightcontrolled room and received a diet of lucerne chaff and 
food pellets providing $75 \mathrm{mmol}$ sodium and $150 \mathrm{mmol}$ potassium per day. Under general anesthesia (induced by $17 \mathrm{mg} / \mathrm{kg}$ thiopentone sodium and maintained by a mixture of halothane, nitrous oxide and oxygen) a Konigsberg (P4-0) high-fidelity pressure-tip transducer was implanted in a carotid artery (Konigsberg Instruments, Pasadena, CA, USA) for direct measurement of mean arterial pressure (MAP) and heart rate. Polyethylene catheters were placed in the jugular veins for infusions, blood sampling and measurement of right atrial pressure (RAP) and a SwanGanz thermodilution catheter (Edwards Lifesciences, Irvine, CA, USA) was placed in the pulmonary artery via the jugular vein for the measurement of cardiac output and mean pulmonary artery pressure (MPAP). A foley catheter was placed per urethra in the bladder to allow continuous collection of urine. The animals were allowed to recover for at least 7 days before experiments commenced.

Each animal was studied on two occasions at least 2 days apart. On one occasion they received intravenous ADM $(33 \mathrm{ng} / \mathrm{kg}$ per $\min =5.5 \mathrm{pmol} / \mathrm{kg}$ per $\mathrm{min}$ ) in $50 \mathrm{ml}$ haemaccel over $90 \mathrm{~min}$, commencing at $0930 \mathrm{~h}$. On the other occasion they received vehicle control $(50 \mathrm{ml}$ haemaccel alone over $90 \mathrm{~min}$ ). Human ADM-52 was synthesized as previously described (Charles et al. 1997). ADM and control were administered according to a balanced random design. Thirty minutes after commencement of ADM/control infusions (1000 h), an acute volume load was administered by intravenous infusion of $6 \%$ Dextran 70 (Baxter, Old Toongabbie, NSW, Australia) in $0.9 \%$ saline at a dose of $15 \mathrm{ml} / \mathrm{kg}$ over $30 \mathrm{~min}$.

Hemodynamic measurements commenced $30 \mathrm{~min}$ before infusions and continued at 30-min intervals (and at the midpoint of volume loading) until $240 \mathrm{~min}$ post volume load. Measurements were obtained by an online data acquisition system (Dataflow, Crystal Biotech, Hopkinton, MA, USA). Heart rate and pressures (MAP, RAP and MPAP) were digitally integrated in 30-s recording periods and data from four consecutive periods were averaged and recorded at preset intervals throughout the study. Cardiac output (thermodilution) was measured in triplicate (three values within 10\%). Calculated total peripheral resistance (CTPR) was MAP divided by cardiac output.

Venous blood was drawn at 30-min intervals throughout the study and at the midpoint of volume loading. Blood was taken into chilled EDTA tubes and centrifuged, and the plasma stored at $-80{ }^{\circ} \mathrm{C}$ before assay for ADM (Lewis et al. 1996), ANP (Charles et al. 1990), brain natriuretic peptide (BNP) (Pemberton et al. 1997), cyclic guanosine monophosphate (cGMP) (Charles et al. 1990), cAMP (Biotrak, Amersham, Bucks, UK), aldosterone (Lun et al. 1983), adrenocorticotropin (ACTH) (Donald 1977), cortisol (Lewis et al. 1992) and plasma renin activity (PRA) (Dunn \& Espiner 1976).

Urine was collected overnight prior to study and then at 30-min intervals throughout the study. Volume was

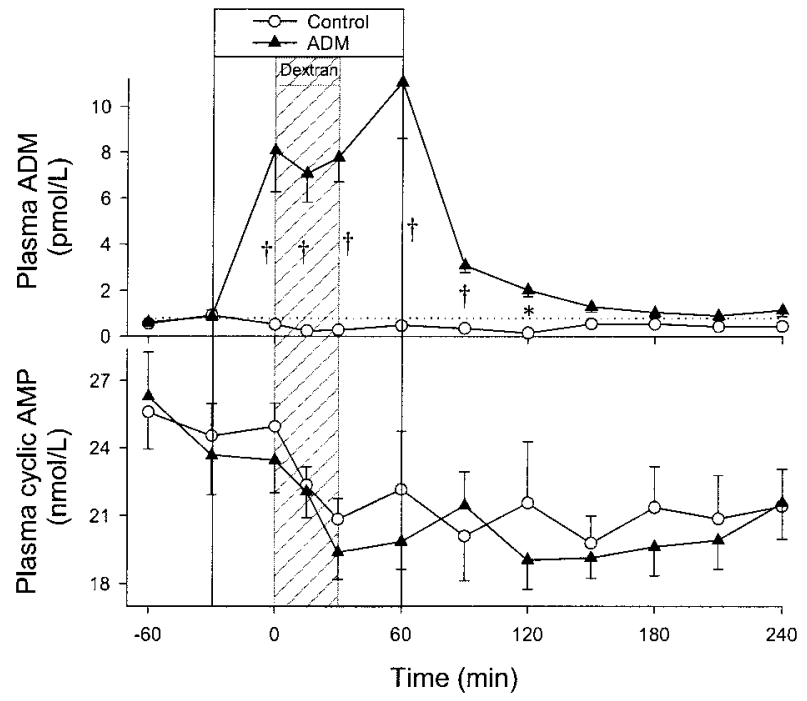

Figure 1 Plasma ADM and CAMP responses to an acute volume load (dextran $-15 \mathrm{ml} / \mathrm{kg}$ ) during intravenous infusions of ADM ( $5.5 \mathrm{pmol} / \mathrm{kg}$ per $\mathrm{min}$ ) or vehicle control in eight sheep. Values shown are means \pm S.E.M. Dotted line represents level of detection in the ADM assay. Plasma ADM $(P<0 \cdot 001)$ was increased during ADM infusion. Individual time points significantly different from time-matched control (Fisher's protected LSD) are indicated by ${ }^{*} P<0 \cdot 05$ and $+P<0 \cdot 01$.

measured prior to assay for sodium, potassium, creatinine and cGMP excretion rates.

\section{Statistics}

Results are expressed as means \pm S.E.M. Two-way ANOVA with time as a repeated measure was used to determine time and treatment differences between ADM and control arms of the study. Statistical significance was assumed at $P<0 \cdot 05$. Where significant differences were identified by ANOVA, a priori Fisher's protected least square difference (LSD) tests were used to identify timepoints significantly different from time-matched control.

\section{Results}

Experiments were completed without mishap and data collection was complete. Plasma immunoreactive (IR) ADM levels remained at or below detection limit for the assay during vehicle control infusions but rose during ADM infusions $(P<0 \cdot 001)$ to $8-11 \mathrm{pmol} / 1$ (Fig. 1). Plasma cAMP levels (a proposed second messenger for ADM) were not altered by ADM.

Dextran loading induced a similar decrease in hematocrit on both study days $(P<0 \cdot 001$ by one-way ANOVA for both, Fig. 2) falling from baselines of $25 \cdot 1 \pm 1 \cdot 8$ and $24 \cdot 8 \pm 1 \cdot 8$ to $18 \cdot 3 \pm 1 \cdot 2$ and $17 \cdot 2 \pm 1 \cdot 4 \%$ during control and ADM respectively (not significant, NS). This reflects acute plasma volume expansion of 27 and $30 \%$ respectively 


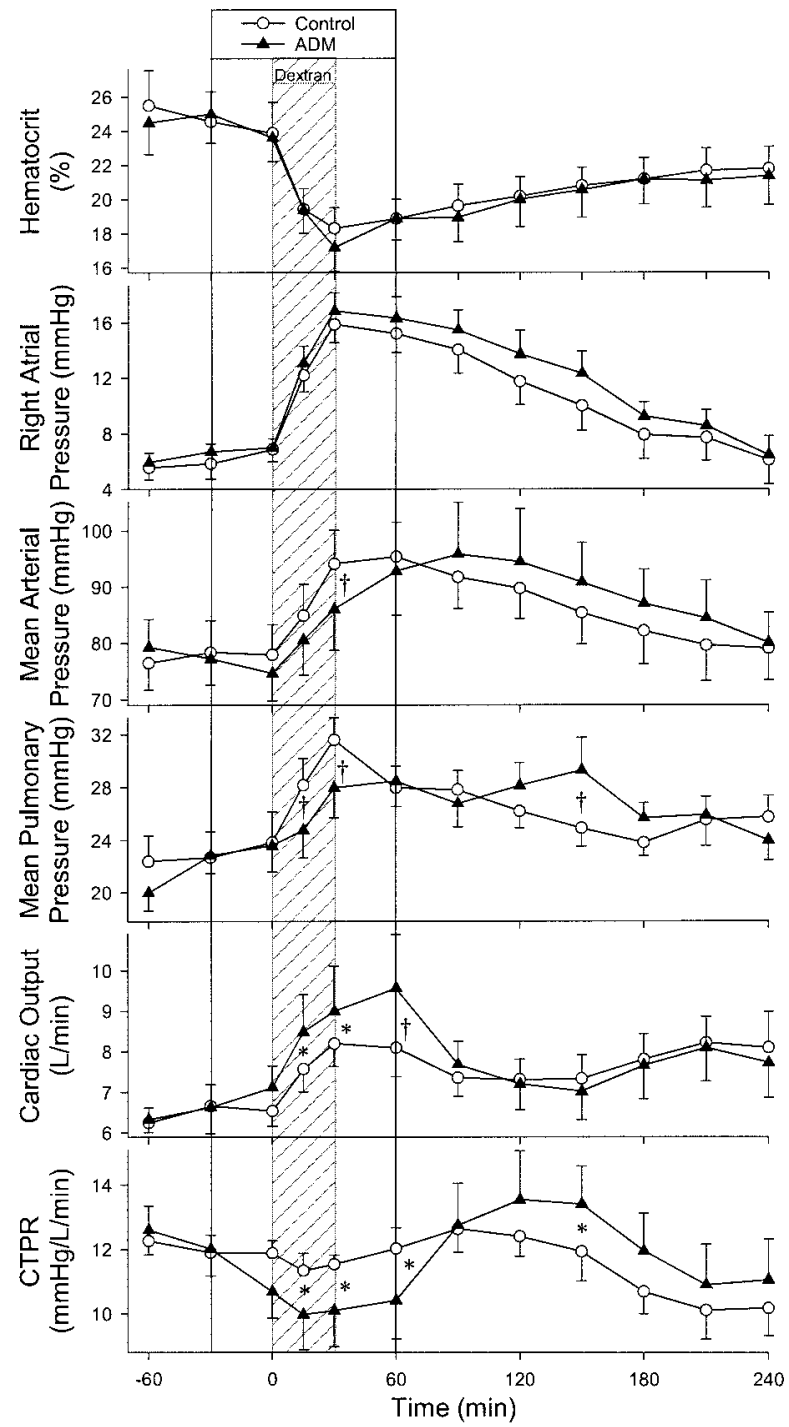

Figure 2 Hemodynamic responses to an acute volume load (dextran $-15 \mathrm{ml} / \mathrm{kg}$ ) during intravenous infusions of adrenomedullin (ADM $-5.5 \mathrm{pmol} / \mathrm{kg}$ per $\mathrm{min}$ ) or vehicle control in eight sheep. Values shown are means \pm S.E.M. Mean arterial pressure $(P=0.033$ by two-way ANOVA), pulmonary pressure $(P=0.005)$ and calculated total peripheral resistance (CTPR $P=0.004)$ were reduced during ADM. Cardiac output was increased during $\operatorname{ADM}(P=0 \cdot 048)$. Individual time points significantly different from time-matched control (Fisher's protected LSD) are indicated by ${ }^{*} P<0.05$ and $+P<0 \cdot 01$.

over the 30-min infusion period. Increases in RAP (approximately $10 \mathrm{mmHg}$ ) were also similar on the two experimental days with pressures returning to baseline values by $3 \mathrm{~h}$ post-dextran. The MAP response to dextran was significantly altered by ADM $(P=0 \cdot 033)$, with pressures being lower during and higher after ADM infusions compared with control. Likewise, ADM induced a biphasic response in MPAP in response to dextran loading

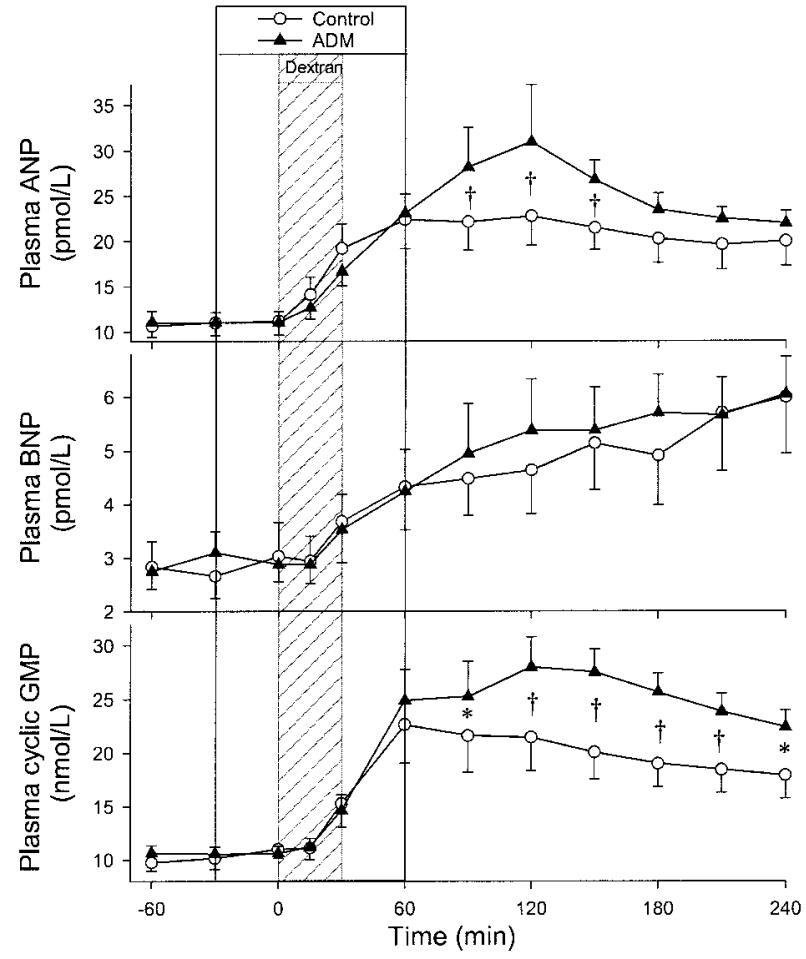

Figure 3 Plasma hormone responses to an acute volume load (dextran $-15 \mathrm{ml} / \mathrm{kg}$ ) during intravenous infusions of adrenomedullin (ADM - 5.5 pmol/kg per min) or vehicle control in eight sheep. Values shown are means \pm S.E.M. Plasma ANP $(P=0.008)$ and cGMP $(P=0 \cdot 003)$ levels were increased following ADM. Individual time points significantly different from time-matched control (Fisher's protected LSD) are indicated by ${ }^{*} P<0 \cdot 05$ and $+P<0 \cdot 01$.

$(P=0 \cdot 005)$ with pressures lower than time-matched control during ADM infusion and higher post-infusion. The rise in cardiac output induced by dextran loading was augmented during ADM infusion $(P=0 \cdot 048)$ and was $1.51 / \mathrm{min}$ greater than control at the completion of ADM infusion. CTPR was significantly altered by ADM $(P=0 \cdot 004)$, being reduced during and raised after ADM compared with control. Heart rate did not change throughout the study (data not shown).

The expected ANP and cGMP responses to dextran loading were significantly enhanced by ADM compared with control $(P=0.008$ and $P=0.003$ respectively) during the post-infusion period (Fig. 3). Plasma BNP levels were increased similarly in response to dextran loading on both $\mathrm{ADM}$ and control days. The dextran-induced fall in PRA $(P=0.039)$ but not aldosterone was attenuated by ADM (Fig. 4). ADM did not affect the ACTH or cortisol responses to dextran loading.

Urinary volume increased in response to dextran loading on both study days (Fig. 5) with a trend for a greater effect after ADM infusion (NS). Calculation of cumulative excess urinary volume over baseline showed a trend for 


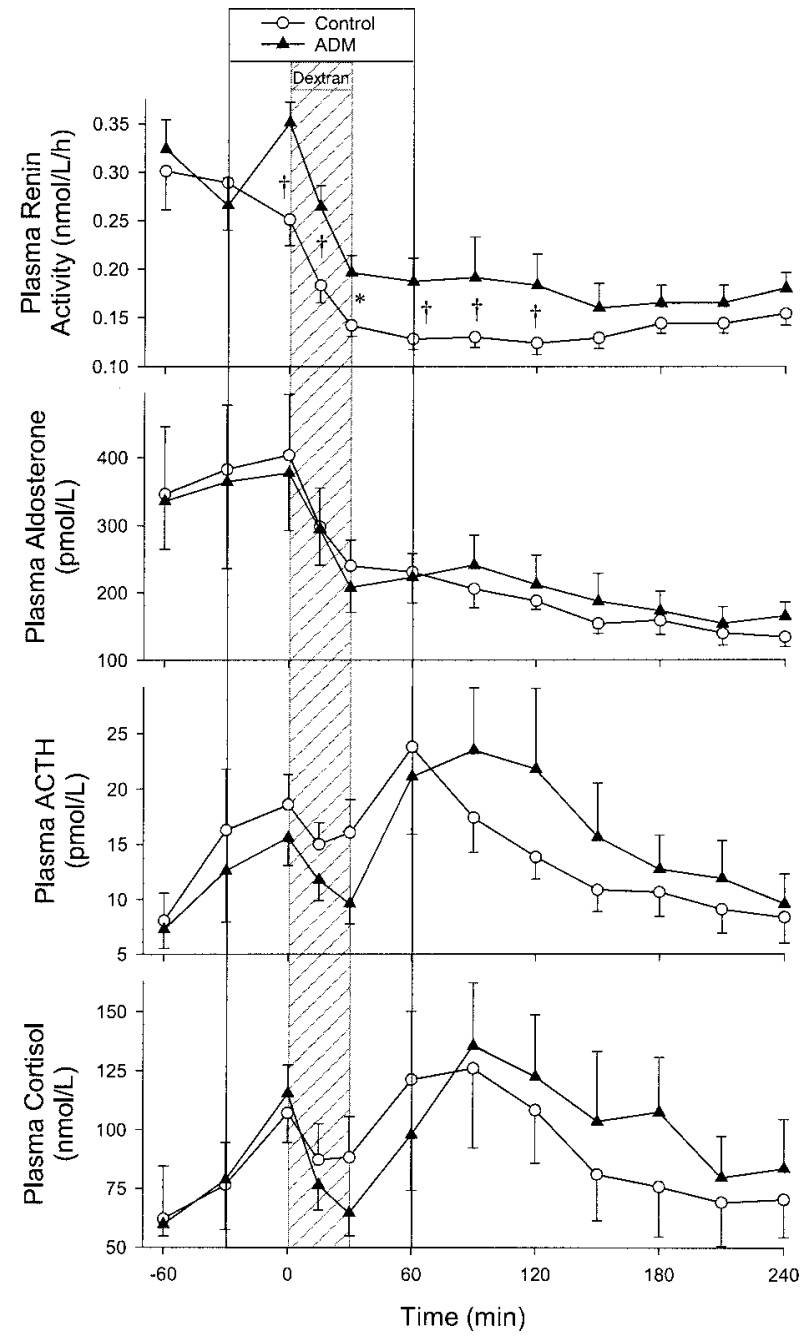

Figure 4 Plasma hormone responses to an acute volume load (dextran $-15 \mathrm{ml} / \mathrm{kg}$ ) during intravenous infusions of adrenomedullin (ADM $-5.5 \mathrm{pmol} / \mathrm{kg}$ per $\mathrm{min}$ ) or vehicle control in eight sheep. Values shown are means \pm S.E.M. The fall in PRA was attenuated by ADM $(P=0 \cdot 039)$. Individual time points significantly different from time-matched control (Fisher's protected LSD) are indicated by ${ }^{*} P<0.05$ and $+P<0 \cdot 01$.

greater volumes on the ADM day (control; $893 \pm 157$ vs ADM; $1263 \pm 179 \mathrm{ml}, 0 \cdot 05<P<0 \cdot 1$ ) with similar volumes during the first $2 \mathrm{~h}$ post-dextran but greater volumes during the second 2-h clearance period post-dextran on the ADM day (control; $367 \pm 71$ vs ADM; $648 \pm 96 \mathrm{ml}$, $P<0 \cdot 05)$. Sodium, potassium and cGMP excretion were increased similarly in response to dextran loading on both study days. Creatinine excretion was not affected on either study day.

\section{Discussion}

Whilst a number of studies postulate a role for ADM in volume and pressure homeostasis, little is known regarding

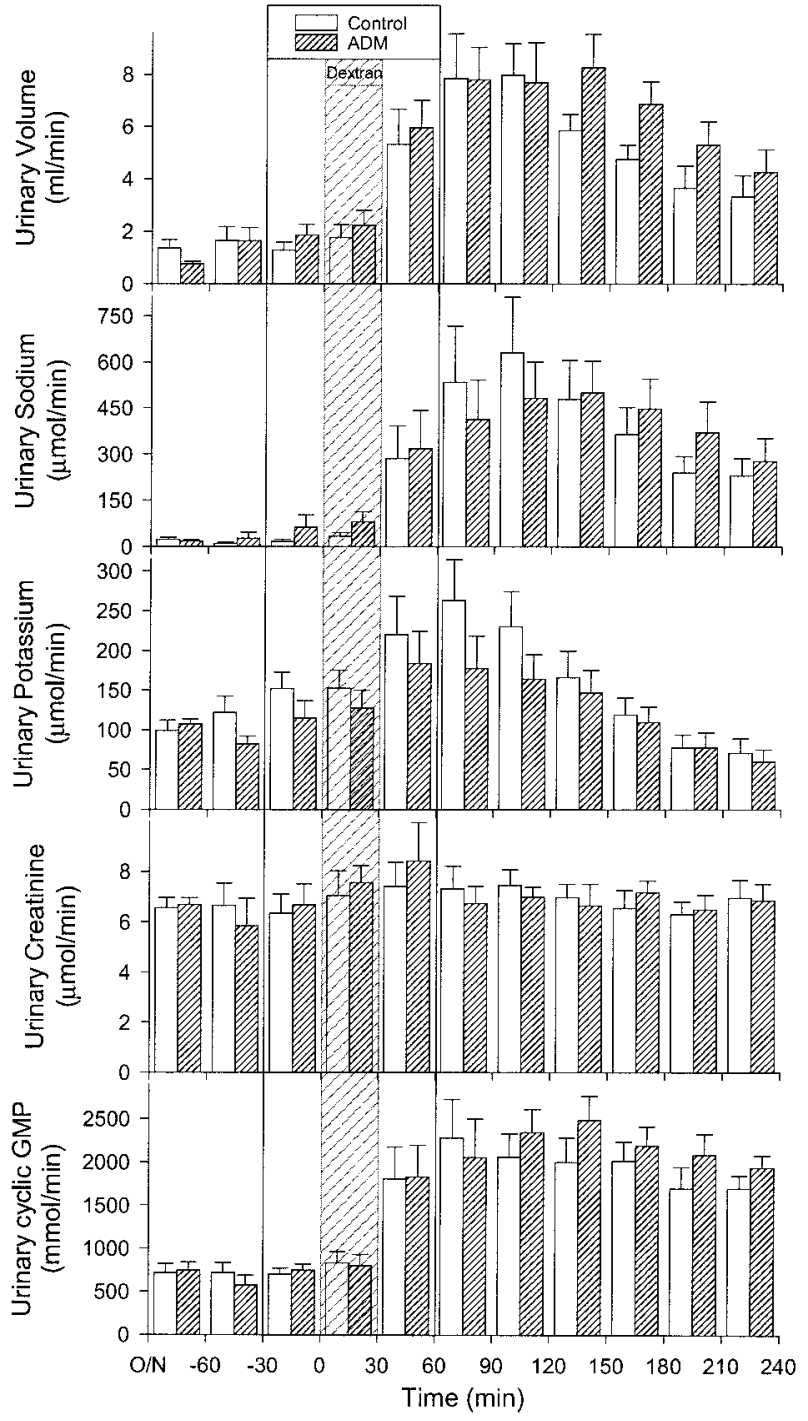

Figure 5 Urinary volume and electrolyte responses to an acute volume load (dextran $-15 \mathrm{ml} / \mathrm{kg}$ ) during intravenous infusions of adrenomedullin (ADM $-5.5 \mathrm{pmol} / \mathrm{kg}$ per $\mathrm{min}$ ) or vehicle control in eight sheep. Values shown are means \pm S.E.M.

effects of ADM in the setting of acute volume loading. Accordingly, we have assessed the effects of a low-dose infusion of ADM, sufficient to increase its circulating levels by $10 \mathrm{pmol} / \mathrm{l}$, on the hemodynamic, hormonal and renal responses to an acute volume (dextran) load in normal conscious sheep. Dextran loading induced similar falls in hematocrit during control and ADM (plasma volume expansion of $27 \%$ and $30 \%$ respectively) and similar increases in RAP (approximately $10 \mathrm{mmHg}$ ). However, compared with changes on the control day, MAP, MPAP and CTPR were reduced and cardiac output increased during ADM administration. MPAP and CTPR demonstrated rebound activation above control 
levels on cessation of ADM infusions. Likewise, plasma ANP and cGMP levels were increased post ADM infusion. ADM also inhibited the fall in PRA but had no significant effects on the responses of other hormones measured. Urine volume was increased marginally by ADM during the final 2-h clearance period (post-infusion).

Hemodynamic effects of ADM have consistently been reported including a lowering of arterial pressure associated with increases in cardiac output and falls in peripheral resistance in normal euvolemic states (Parkes \& May 1995, Charles et al. 1997, Lainchbury et al. 1997). Whilst there have been a number of studies reporting increased endogenous plasma ADM levels in hypervolemic states, particularly congestive heart failure and chronic renal disease (Mallamaci et al. 1998), to our knowledge, there are no reports on the hemodynamic actions of infused $\mathrm{ADM}$ in the setting of acute volume expansion. In the present study, ADM attenuated the acute rises in MAP and MPAP in response to dextran loading, whereas both indices trended higher upon cessation of ADM compared with time-matched control. These relative reductions in arterial and pulmonary pressures were apparent despite a matched fall in hematocrit and matched rises in filling pressures (RAP). The rise in cardiac output observed with dextran loading alone (control data) was further enhanced by ADM, consistent with effects of ADM in euvolemic sheep (Parkes \& May 1995; Charles et al. 1997). ADM's effect on cardiac output may be due in part to its powerful positive inotropic action previously reported (Parkes \& May 1995, Szokodi et al. 1998). As with previous studies in euvolemic animals, there was a reduction in CTPR which would also tend to promote increased cardiac output due to reduced afterload. Thus, available evidence points to ADM being a potent vasodilator probably via a direct action of ADM on arterial tone (Champion et al. 1997, Cockcroft et al. 1997). Although extrapolation from acute to chronic states should be made with caution, these findings suggest that the elevated levels of ADM observed in heart failure may provide a compensatory effect maintaining cardiac output and reducing afterload in the face of inappropriate volume expansion.

Previous reports of ADM's effects on the natriuretic peptides have been inconsistent. An in vitro study has reported suppression of ANP mRNA expression by ADM in neonatal rat cardiocytes (Sato et al. 1997). In contrast, in vivo data from our laboratory suggests ADM may stimulate plasma ANP and BNP levels. In an ovine pacing model of heart failure, we have consistently shown that plasma natriuretic peptide levels remain elevated during ADM infusion despite precipitous falls in filling pressures (Rademaker et al. 1997 and unpublished observations). Furthermore, plasma ANP and BNP levels increase significantly post-ADM infusion concurrent with filling pressures returning to baseline levels. These studies contrast sharply with previous studies demonstrating a close correlation between falls in filling pressures and plasma ANP and BNP after administration of other vasodilators such as renin inhibitors and angiotensin converting enzyme (ACE) inhibitors in paced sheep (Fitzpatrick et al. 1992). In the present study performed in normal sheep, the plasma ANP and BNP responses to acute volume loading were maintained during concomitant ADM infusion despite the fact that MAP was reduced. Furthermore, ANP and cGMP levels were significantly augmented above control data post-ADM infusion. The reason for this delayed accentuation of ANP by ADM is not clear. First, it is difficult to postulate a direct stimulatory action of ADM itself on ANP secretion since levels of ADM were falling precipitously at a time when ANP levels were augmented. Secondly, RAP was slightly (but not significantly) higher post-ADM infusion compared with control. It is conceivable that left atrial pressures might likewise have been higher post-ADM and future studies need to address this possibility. Thirdly, it is possible that ADM may promote natriuretic peptide secretion indirectly via stimulation of angiotensin II, a known secretagogue for natriuretic peptides (Ruskoaho 1992). Although not measured in the present study, angiotensin II levels presumably were higher compared with control levels in parallel with the observed increments in PRA. Whatever the explanation, plasma levels of cGMP, the intracellular messenger for the natriuretic peptides, showed an identical pattern with the response to dextran loading being augmented by ADM. The pattern of response for BNP was similar although not statistically significant. Thus, the results of the present study supports earlier data that ADM can stimulate natriuretic peptide secretion in vivo but whether this is by direct or indirect means remains to be determined. Taken together, these findings suggest ADM infusions have 'reset' the relationship between changes in filling pressure and consequent natriuretic peptide release. Again this would suggest a compensatory mechanism improving adaptation to volume challenge by virtue of the natriuretic, vasodilatory and reninaldosterone suppressant actions of the natriuretic peptides.

Stimulation of PRA by ADM is a consistent finding in sheep (Parkes \& May 1995, Charles et al. 1997, Rademaker et al. 1997). ADM induced rapid activation of PRA (pre-dextran) and then attenuated the dextraninduced decline in PRA. It is of interest that ADM enhanced PRA following dextran loading despite the increased delivery of sodium to the macula densa, which would normally inhibit renin secretion (Davis \& Freeman 1976). The mechanisms underlying this stimulation of renin cannot be determined from our study but might include the lower renal perfusion pressure with ADM compared with control and a direct action of the peptide on the juxtaglomerular apparatus (Jensen et al. 1997). Despite the higher levels of PRA with ADM than vehicle control, plasma aldosterone levels remained similar to control levels, consistent with relative inhibition of 
aldosterone secretion by ADM as observed previously by others (Nussdorfer et al. 1997, Petrie et al. 2000, Salemi et al. 2000).

Intra-renal administration of ADM has been reported to be natriuretic and diuretic in anesthetized rats (Hirata et al. 1995) and dogs (Ebara et al. 1994). Furthermore, ADM is natriuretic in an ovine pacing model of heart failure (Rademaker et al. 1997). Fewer studies have reported diuresis or natriuresis in normal animals or man at physiologically relevant doses of ADM (Charles et al. 1997, Lainchbury et al. 1997, Troughton et al. 2000). However, we have observed that modest increments in plasma ADM are clearly diuretic and natriuretic in normal sheep relative to infusions of nitroprusside which induced matched falls in arterial pressure (and presumably renal perfusion pressure) (Charles et al. 2001). Further, McGregor et al. (2001) observed that ADM was diuretic and natriuretic in patients with $\operatorname{IgA}$ nephropathy. In the present study, the large diuretic and natriuretic response to dextran loading may have masked any subtle effects of ADM to increase urinary volume and sodium excretion above timematched control. Nevertheless, ADM did augment the diuretic and arguably the natriuretic (NS) responses to dextran. These effects were delayed and concomitant with higher levels of ANP, cGMP and arterial pressure.

Since the amino acid sequence of ovine ADM is yet to be determined we infused the human form in the present studies. There is a high degree of homology for ADM between species sequences thus far identified (Richards et al. 1996). On the other hand, it appears that bioactivity may be species specific (Kohno et al. 1996), hence it will ultimately be important to determine the biological actions of the hormone in the species of origin. Using an assay developed for measuring ADM in human plasma (Lewis et al. 1996), we could not confirm detectable IR-ADM in sheep plasma - endogenous levels were at or below the detection limit of the assay. Nevertheless, at the dose employed in the present study, achieved plasma levels of approximately $10 \mathrm{pmol} / 1$ are at the upper limit of physiological for humans (normal range in our laboratory with this assay is $2 \cdot 7-10 \cdot 1 \mathrm{pmol} / \mathrm{l}$ ) and the increment is well within the range observed after myocardial infarction or in clinical heart failure. As such, it is likely that biological activity observed at these circulating levels has physiological and pathophysiological relevance.

In conclusion, low-dose infusions of ADM administered to conscious sheep exhibit hemodynamic and hormonal actions in the setting of acute volume loading including enhanced natriuretic peptide secretion. Taken together, these results suggest that ADM may contribute to the adaptation to volume challenge by promoting sustained cardiac output through reducing afterload and directly and indirectly facilitating excretion of water and sodium. These results provide further evidence that ADM may play a physiological role in volume and pressure homeostasis.

\section{Acknowledgements}

We are grateful to staff of the Christchurch School of Medicine Animal Laboratory for assistance with animal studies and Christchurch Cardioendocrine Laboratory staff for hormone assays. Support was provided through grants from the Heart Foundation of New Zealand, and Health Research Council of New Zealand.

\section{References}

Champion HC, Lambert DG, McWilliams SM, Shah MK, Murphy WA, Coy DH \& Kadowitz PJ 1997 Comparison of responses to rat and human adrenomedullin in the hindlimb vascular bed of the cat Regulatory Peptides 70 161-165.

Charles CJ, Espiner EA, Cameron VA \& Richards AM 1990 Hemodynamic, renal, and endocrine actions of ANF in sheep: effect of 24-h, low-dose infusions. American Journal of Physiology 258 R1279-R1285.

Charles CJ, Tang F, Cameron VA, Richards AM \& Espiner EA 1991 Intracerebroventricular atrial natriuretic factor (ANF) antiserum inhibits volume-induced ANF in sheep: evidence for the brain's regulation of ANF secretion. Endocrinology 129 $2225-2230$

Charles CJ, Rademaker MT, Richards AM, Cooper GJS, Coy DH, Jing NY \& Nicholls MG 1997 Hemodynamic, hormonal, and renal effects of adrenomedullin in conscious sheep. American Journal of Physiology 272 R2040-R2047.

Charles CJ, Nicholls MG, Rademaker MT \& Richards AM 2001 Comparative actions of adrenomedullin and nitroprusside: interactions with angiotensin II and norepinephrine. American Journal of Physiology 281 R1887-R1894.

Cockcroft JR, Noon JP, Gardner-Medwin J \& Bennett T 1997 Haemodynamic effects of adrenomedullin in human resistance and capacitance vessels. British Journal of Clinical Pharmacology 44 57-60.

Davis JO \& Freeman RH 1976 Mechanisms regulating renin release. Physiological Reviews 56 1-46.

Donald RA 1977 Radioimmunoassay of corticotropin (ACTH). In Handbook of Radioimmunoassay, pp 319-390. Ed G Abrahams. New York: Marcel Dekker.

Dunn PJ \& Espiner EA 1976 Outpatient screening tests for primary aldosteronism. Australian and New Zealand Journal of Medicine $\mathbf{6}$ 131-135.

Ebara T, Miura K, Okumura M, Matsuura T, Kim S, Yukimura T \& Iwao H 1994 Effect of adrenomedullin on renal hemodynamics and functions in dogs. European Journal of Pharmacology 263 69-73.

Fitzpatrick MA, Rademaker MT, Charles CJ, Yandle TG, Espiner EA, Ikram H \& Nussburger J 1992 Comparison of the effect of renin inhibition and angiotensin-converting enzyme inhibition in ovine heart failure. Journal of Cardiovascular Pharmacology 19 169-175.

Hirata Y, Hayakawa H, Suzuki Y, Suzuki E, Ikenouchi H, Kohmoto O, Kimura K, Eto T, Kangawa K, Matsuo H \& Omata M 1995 Mechanisms of adrenomedullin-induced vasodilation in rat kidneys. Hypertension 25 790-795.

Jensen BL, Kramer BK \& Kurtz A 1997 Adrenomedullin stimulates renin release and renin mRNA in mouse juxtaglomerular granular cells. Hypertension 29 1148-1155.

Kohno M, Yasunari K, Yokokawa K, Horio T, Ikeda M, Kano H, Minami M, Hanehira T \& Yoshisawa J 1996 Interaction of adrenomedullin and platelet-derived growth factor on rat mesangial cell production of endothelin. Hypertension 27 663-667.

Lainchbury JG, Cooper GJS, Coy DH, Jiang NY, Lewis LK, Yandle TG, Richards AM \& Nicholls MG 1997 Adrenomedullin: a hypotensive hormone in man. Clinical Science 92 467-472. 
Lewis JG, Manley L, Whitlow JC \& Elder PA 1992 Production of a monoclonal antibody to cortisol: application to a direct immunosorbent assay of plasma. Steroids 57 82-85.

Lewis LK, Smith MW, Charles CJ, Lainchbury JG, Yandle TG, Richards AM \& Nicholls MG 1996 Plasma assay and in vivo kinetics of human adrenomedullin (1-52) in humans and sheep. (Abstract). Proceedings of the 10th International Congress of Endocrinology, San Francisco, CA, USA, Abstract P1-P768.

Lun S, Espiner EA, Nicholls MG \& Yandle TG 1983 A direct radioimmunoassay for aldosterone in plasma. Clinical Chemistry 29 268-271.

McGregor DO, Troughton RW, Frampton C, Lynn KL, Yandle T, Richards AM \& Nicholls G 2001 Hypotensive and natriuretic actions of adrenomedullin in subjects with chronic renal impairment. Hypertension 37 1279-1284.

Mallamaci F, Zoccali C, Parlongo S, Cutrupi S, Tripepi G \& Postorino M 1998 Plasma adrenomedullin during acute changes in intravascular volume in hemodialysis patients. Kidney International $\mathbf{5 4}$ 1697-1703

Nussdorfer GG, Rossi GP \& Mazzocchi G 1997 Role of adrenomedullin and related peptides in the regulation of the hypothalamo-pituitary-adrenal axis. Peptides 181079-181089.

Parkes DG \& May CN 1995 ACTH-suppressive and vasodilator actions of adrenomedullin in conscious sheep. Journal of Neuroendocrinology 7 923-929.

Pemberton CJ, Yandle TG, Charles CJ, Rademaker MT, Aitken GD \& Espiner EA 1997 Ovine brain natriuretic peptide in cardiac tissues and plasma: effects of cardiac hypertrophy and heart failure on tissue concentration and molecular forms. Journal of Endocrinology 155 541-550.
Petrie MC, Hiller C, Morton JJ \& McMurray JJ 2000 Adrenomedullin selectively inhibits angiotensin II-induced aldosterone secretion in humans. Journal of Hypertension 18 61-64.

Rademaker MT, Charles CJ, Lewis LK, Yandle TG, Cooper GJS, Coy DH, Richards AM \& Nicholls MG 1997 Beneficial hemodynamic and renal effects of adrenomedullin in an ovine model of heart failure. Circulation 96 1983-1990.

Richards AM, Nicholls MG, Lewis L \& Lainchbury JG 1996 Adrenomedullin. Clinical Science 91 3-16.

Ruskoaho H 1992 Atrial natriuretic peptide: synthesis, release and metabolism. Pharmacological Reviews 44 479-602.

Salemi R, McDougall JG, Hardy KJ \& Wintour EM 2000 Effect of adrenomedullin infusion on basal and stimulated aldosterone secretion in conscious sheep with cervical adrenal autotransplants. Journal of Endocrinology 166 389-399.

Sato A, Canny BJ \& Auteliatano DJ 1997 Adrenomedullin stimulates cAMP accumulation and inhibits atrial natriuretic peptide gene expression in cardiomyocytes. Biochemical and Biophysical Research Communications 230 311-314.

Szokodi I, Kunnunen P, Tavi P, Weckstrom M, Toth M \& Ruskoaho H 1998 Evidence for cAMP-independent mechanisms mediating the effects of adrenomedullin, a new inotropic peptide. Circulation 97 1062-1070.

Troughton RW, Lewis LK, Yandle TG, Richards AM \& Nicholls MG 2000 Hemodynamic, hormone and urinary effects of adrenomedullin infusion in essential hypertension. Hypertension 36 588-593.

Received 24 August 2001

Accepted 7 December 2001 